\title{
Omega-3 fatty acids: anti-arrhythmic, pro-arrhythmic, or both?
}

\section{C. von Schacky*}

Preventive Cardiology, Medizinische Klinik and Poliklinik I, Ludwig Maximilians-University Munich, Munich, Germany

\section{Edited by:}

George E. Billman, The Ohio State University, USA

\section{Reviewed by:}

Ruben Coronel, Academic Medical Center, Netherlands

David R. Van Wagoner, Cleveland

Clinic Lerner College of Medicine of

Case Western Reserve University,

USA

\section{*Correspondence:}

C. von Schacky, Preventive Cardiology, Medizinische Klinik and Poliklinik I, Ludwig MaximiliansUniversity Munich, Ziemssenstr. 1, 80336 Munich, Germany. e-mail: clemens.vonschacky@med. uni-muenchen.de
This review focuses on developments after 2008, when the topic was last reviewed by the author. Pertinent publications were found by medline searches and in the author's personal data base. Prevention of atrial fibrillation (AF) was investigated in a number of trials, sparked by one positive report on the effects of eicosapentaenoic acid (EPA) and docosahexaenoic acid (DHA), considerations of upstream therapy, data from electrophysiologic laboratories and animal experiments. If EPA $+\mathrm{DHA}$ prevent postoperative $A F$, the effect is probably smaller than initially expected. The same is probably true for maintenance of sinus rhythm after cardioversion and for new-onset AF. Larger trials are currently ongoing. Prevention of ventricular arrhythmias was studied in carriers of an implanted cardioverterdefibrillator, with no clear results. This might have been due to a broad definition of the primary endpoint, including any ventricular arrhythmia and any action of the device. Epidemiologic studies support the contention that high levels of EPA + DHA prevent sudden cardiac death (SCD). However, since SCD is a rare occurrence, it is difficult to conduct an adequately powered trial. In patients with congestive heart failure, EPA + DHA reduced total mortality and rehospitalizations, but not SCD or presumed arrhythmic death. Of three trials in patients after a myocardial infarction, two were inadequately powered, and in one, the dose might have been too low. Taken together, while epidemiologic studies support an inverse relation between EPA + DHA and occurrence of SCD or arrhythmic death, demonstrating this effect in intervention trials remained elusive so far. A pro-arrhythmic effect of $E P A+D H A$ has not been seen in intervention studies, and results of epidemiologic and animal studies also rather argue against such an effect. A different, and probably more productive, perspective is provided by a standardized analytical assessment of a person's status in EPA + DHA by use of the omega- 3 index, EPA + DHA in red cell fatty acids. In populations with a high omega- 3 index, SCD is rare. Intervention trials can become more effective by including a low omega-3 index into the inclusion criteria, thus creating a study population more likely to demonstrate an effect of EPA + DHA. This is especially relevant in case of rare endpoints, like new-onset AF or SCD.

Keywords: eicosapentaenoic acid, docosahexaenoic acid, omega-3 fatty acids, omega-3 index, atrial fibrillation, ventricular tachycardia, ventricular fibrillation, sudden cardiac death

\section{INTRODUCTION}

The view that the two marine omega-3 fatty acids eicosapentaenoic acid (EPA) and docosahexaenoic acid (DHA) impact on cardiac rhythm goes back a number of years, and has been reviewed by this author in 2008 (von Schacky, 2008). Underlying mechanisms have recently been reviewed (Richardson et al., 2011). The impression that EPA + DHA are primarily antiarrhythmic has been challenged by results of clinical studies, reporting that EPA and DHA did not reduce sudden cardiac death (SCD; Rauch et al., 2010). Moreover, in one study, it had been reported that higher levels of EPA and DHA in red blood cells

Abbreviations: AF, atrial fibrillation; CI, confidence interval; DHA, docosahexaenoic acid; EPA, eicosapentaenoic acid; HR, hazard ratio; ICD, implanted cardioverter-defibrillator; SCD, sudden cardiac death; VF, ventricular fibrillation; VT, ventricular tachycardia. were associated with a higher likelihood of ventricular arrhythmias (Wilhelm et al., 2008). These results are in contrast to the manifold evidence present already in 2008, indicating antiarrhythmic effects of EPA and DHA (von Schacky, 2008). The present review will highlight recent developments and put them into perspective.

\section{METHOD}

Medline searches were performed with the combination of "omega-3," " $n-3$ fatty acids" "eicosapentaenoic," or "docosahexaenoic" with "arrhythmia," and investigations conducted in humans and fully published in more recent years than 2008 were selected. Studies on animals were also included, in case animals were pre-fed with omega-3 fatty acids. In addition, the author's personal base of publications was used. Abstracts presented at scientific meetings were not included. 


\section{ANIMAL STUDIES}

Experiments on ion channels in cultured cells, on cardiac tissue in vitro, Langendorff preparations of explanted hearts, or using similar techniques investigating acute effects of EPA and/or DHA are reviewed elsewhere (De Caterina, 2011; Mozaffarian and Wu, 2011; Richardson et al., 2011; Savelieva et al., 2011). Of note, in such studies biologically active metabolites of EPA and DHA were defined, making the developments of more effective compounds a distinct possibility (e.g., Falck et al., 2011).

\section{CARDIAC RHYTHM}

Heart rate and heart rate variability were recorded at rest, during submaximal exercise, and during a 2-min coronary artery occlusion at rest in dogs with a healed myocardial infarction before and after 3 months supplementation with a fish oil or corn oil. Fish oil, but not corn oil reduced heart rate and heart variability at rest, but not during exercise or during coronary occlusion (Billman and Harris, 2011).

\section{NEW-ONSET POSTOPERATIVE AF}

Dogs were fed a fish oil-enriched chow (or control) for 3 weeks before excision of the left atrial appendage. Burst pacing induced atrial fibrillation (AF) only in control dogs, whereas postoperative atrial effective refractory period was prolonged, heart rate was lower, and heart rate variability higher in the fish oil-fed dogs. Less postoperative inflammatory reaction was observed in the atria of fish oil-fed dogs (Mayyas et al., 2011).

\section{NEW-ONSET AF}

After 7 days feeding of a fish oil or a control chow, dogs were atrioventricularly paced at $220 \mathrm{bpm}$ for 14 days (feeding was continued). A third group of dogs was fed a regular chow and was not paced. Atrial tissue was sampled and analyzed for gene expression using a quantitative reverse real-time polymerase chain reaction. Genes related to fibrosis, hypertrophy, and inflammation were found to be down-regulated by the fish oil supplement (Ramadeen et al., 2010). More recently, the same group initiated treatment with EPA + DHA 7 days after simultaneous atrial and ventricular pacing was initiated to induce AF (Ramadeen et al., 2012). After a total of 14 days of pacing, no effects of $\mathrm{EPA}+\mathrm{DHA}$ were seen on development of AF, echocardiographic and histologic parameters, and on expression of fibrosis-related genes, which was in contrast to the previous study, where dogs were fed before pacing (Ramadeen et al., 2012). In a similar study, after 7 days of feeding EPA, rabbits were subjected to ventricular pacing at $400 \mathrm{bpm}$ for 4 weeks to induce heart failure (feeding was continued). One group of control rabbits was not fed EPA, one group was not paced. Duration of AF after burst pacing was attenuated in the EPA group, as was atrial fibrosis and a number of inflammatory parameters (Kitamura et al., 2011).

Taken together, these animal studies indicate that the propensity develop AF is mitigated by pre-feeding omega- 3 fatty acids by interactions at various levels - from gene expression to refractory period. However, use of EPA + DHA 7 days after initiation of pacing had no effect. No study was found indicating a pro-arrhythmic effect on the supraventricular level.

\section{VENTRICULAR ARRHYTHMIAS/CELL PREPARATIONS}

Infusion of omega-3 fatty acids corrected some, but not all abnormalities of ventricular ion channel function induced by omega-3 depletion in rats (Peltier et al., 2009).

\section{VENTRICULAR ARRHYTHMIAS/LANGENDORFF PREPARATIONS}

Rats were fed diets enriched in fish oil, sunflower oil, or beef tallow for 6 weeks. The hearts were either subjected to ischemic preconditioning or not. It was found that ischemic preconditioning reduced ventricular arrhythmias in all dietary groups, but mostly so in the fish oil group (Abdukeyum et al., 2008). In another study, rabbits were fed fish oil or a control laboratory chow for 30 days. The hearts were challenged with dofetilide, a selective rapidly activating delayed rectifier potassium current inhibitor with pro-arrhythmic effects. Dofetilide-induced triangulation, reverse use-dependence, instability, and dispersion were reduced and torsade de pointes abolished (Dujardin et al., 2008). Pre-feeding with omega-3 fatty acids did not suppress the incidence of ventricular reperfusion arrhythmias after global no-flow ischemia in hearts of female mice (Huggins et al., 2009). Rats with or without hypertriglyceridemia were given atorvastatin and/or omega- 3 fatty acids for 2 months. Threshold for VF was tested by electrical stimuli. Threshold for VF was lower in hypertriglyceridemic rats, but was significantly increased by omega-3 fatty acids, an effect found to be related to an improvement in cell-to-cell junction integrity (Bacova et al., 2010).

\section{VENTRICULAR ARRHYTHMIAS/WHOLE ANIMAL EXPERIMENTS}

Pericardial infusion of DHA reduced infarct size and ventricular arrhythmias in pigs subjected to experimental myocardial infarction (Xiao et al., 2008). Cells from explanted hearts from rabbits or humans with congestive heart failure were superfused with EPA or DHA. This abolished triggered activity and reduced the number of delayed afterdepolarizations and calcium aftertransients compared with control and oleic acid (Den Ruijter et al., 2008). In aged spontaneously hypertensive rats, fish oil feeding for 2 months suppressed inducible ventricular fibrillations, and improved other cardiac parameters in comparison to untreated controls (Mitasíková et al., 2008). Dogs were subjected to an experimental myocardial infarction, and 4 weeks later randomized to receive omega-3 fatty acids or placebo for 3 months. Ventricular function was then assessed in a number of ways, but no differences were found (Billman et al., 2010). Size of an experimental infarction was smaller in rats given omega- 3 fatty acids than diets rich in saturated or omega- 6 fatty acids (Zeghichi-Hamri et al., 2010). Male pigs were fed EPA or a control chow for 3 weeks, and then a 90-min myocardial ischemia was induced. EPA attenuated occurrence of VF, reduced mortality, and attenuated monophasic action potential duration shortening during ischemia (Tsuburaya et al., 2011). Very recently, results of experiments in dogs with healed myocardial infarction, made ischemic by occlusion of the circumflex artery in the last minute of exercise were reported (Billman et al., 2012). The dogs received either a corn oil placebo or doses of EPA + DHA ranging from 1 to $4 \mathrm{~g}$ /day for 3 months, the latter being incorporated into red cell and cardiac tissue fatty acids. EPA + DHA did not prevent arrhythmias in dogs in which VF could be induced before treatment started (decreased in $27 \%$ 
placebo vs. $24 \% n-3$ PUFA, $p=0.5646)$ but made dogs in which VT or VF could not be induced before treatment susceptible $(n-3$ PUFA 33\% vs. placebo $0 \%, p=0.0442$ ). The authors concluded that dietary $n-3$ PUFAs did not prevent ischemia-induced VF and actually increased arrhythmia susceptibility in both non-infarcted and low-risk post-MI dogs (Billman et al., 2012).

Taken together, pre-feeding omega-3 fatty acids before experimental myocardial infarctions reduced mortality, infarct size and ventricular arrhythmias. However, 4 weeks after an experimental myocardial infarction, feeding omega- 3 fatty acids did not affect ventricular function, and reduced VT's in two, and increased VT's in one study. Most studies of Langendorff preparations of hearts from animals pre-fed with omega- 3 fatty acids indicate a reduced propensity toward ventricular arrhythmias. One study saw no suppression of reperfusion arrhythmias. Taken together, results from animal studies are not homogeneous, and might depend on the model studied. In this authors personal opinion, results from animal studies should have little impact on clinical decisions. Rather, clinical decisions should be guided by data derived from human studies, preferably large intervention trials.

\section{STUDIES IN HUMANS}

\section{SUPRAVENTRICULAR ARRHYTHMIAS}

Aside from epidemiologic observations (Gronroos and Alonso, 2010; Wu et al., 2012), promising results of studies on effects of EPA and DHA on atrial tissue or cells, and a number of animal models mentioned above, and more extensively reviewed in Savelieva et al. (2011), interest in randomized clinical trials was sparked by a trial, in which EPA and DHA prevented new-onset AF in patients after a coronary bypass operation (Calò et al., 2005). Supportive evidence was provided by a small randomized controlled intervention trial on parameters measured in the electrophysiology laboratory in a total of 36 patients, demonstrating that a mean treatment of 40 days with $1.8 \mathrm{~g} /$ day EPA + DHA in a fish oil prolonged pulmonary venous and left atrial effective refractory periods and decreased susceptibility to initiation AF from within pulmonary veins (Kumar et al., 2011a). In two follow-up studies from the same group, using the same approach, it was found that $1.8 \mathrm{~g} /$ day $\mathrm{EPA}+\mathrm{DHA}$ prolonged atrial refractoriness and reduced vulnerability to inducible AF, and attenuated atrial mechanical stunning after reversion of atrial arrhythmias to sinus rhythm (Kumar et al., 2011 b,c). While the results just mentioned were promising, they needed to be scrutinized in trials using occurrence of AF as an endpoint.

\section{New-onset postoperative AF}

For a randomized double-blind single-center study in Germany, 102 patients were recruited before a coronary bypass operation (Heidt et al., 2009). Throughout the hospital stay, they were given $1 \mathrm{ml} / \mathrm{kg}$ body weight/day of an intravenous formulation. In the intervention group of 52 patients, this formulation contained, according to the authors, $10 \mathrm{mg}$ of a fish oil per $100 \mathrm{ml}$, which, again according to the authors, resulted in a dose of $100 \mathrm{mg}$ fish oil/kg body weight/day. According to a reference manual, $100 \mathrm{ml}$ of this formulation contain between 1.25-2.82 g EPA and 1.44-3.09 g DHA (http://new. ch.oddb.org/de/drugs/fachinfo/uid/186817). The control group received a soy-based intravenous formulation, containing $10 \mathrm{~g}$ of soy bean oil per $100 \mathrm{ml}$, resulting in $100 \mathrm{mg}$ soy bean oil/kg body weight/day. Sample size calculation was based on a $30 \%$ occurrence of postoperative AF in the control group and a $20 \%$ occurrence in the intervention group, and testing for significance after each event (but no correction for multiple testing), other assumptions were not reported. Heart rhythm was monitored continuously on the intensive care unit. It is not reported, whether all or how many of the recruited patients were evaluated at study end. According to table 3 of the publication, 3 days postoperatively, 11 patients in the control group (according to the authors 11.58\%), and 7 patients in the intervention group (according to the authors 7.37\%) developed AF. According to the authors, "after the 18th test, the procedure can be stopped with a probability of error of 0.01." In the abstract of the publication, the authors state: "Postoperative AF occurred in 15 patients (according to the authors $30.6 \%$ ) in the control and in 9 (according to the authors $17.3 \%$ ) in the PUFA group $(p<0.05)$." In two figures, a trend toward a shorter hospital stay for patients in sinus rhythm is depicted, but in the abstract, the authors state: "After CABG, the PUFA patients had to be treated in the ICU for a shorter time than the control patients." The authors concluded that "perioperative intravenous infusion of PUFA should be recommended for patients undergoing CABG," because "PUFA reduces the incidence of AF after CABG and leads to a shorter stay in the ICU and in hospital." The latter conclusion does not appear to be supported by a significant difference in hospital stays between control and intervention groups, and the former is based on numbers that are difficult to comprehend.

For another randomized double-blind single-center study, this time in the UK, 108 patients were recruited before a coronary bypass operation (Saravanan et al., 2010). Patients were recruited 1-3 weeks preoperatively, and were given either two $1 \mathrm{~g}$ capsules per day of a $85 \%$ fish oil concentrate in the form of an ethylester (54 patients), or identical capsules containing olive oil as a placebo (54 patients). Sample size was calculated based on an expected incidence of postoperative AF of $50 \%$ in the placebo group and a relative risk reduction of $55 \%$ by EPA and DHA, and the usual assumptions $(\alpha<0.05, \beta=0.8)$. Heart rhythm was monitored continuously with a recorder for 5 days postoperatively, and episodes of AF > 30 s duration were considered. At study end, in the intervention group, 52 patients were analyzed, and 51 in the placebo group. Mean treatment duration was 17 days, and AF developed in $43 \%$ of the placebo group, and $56 \%$ of the intervention group (n.s.). Hospital stay and other parameters were also not significantly different. The authors concluded that "omega-3 PUFA do not reduce the risk of AF after coronary artery bypass graft surgery" (Saravanan et al., 2010).

A similar, randomized double-blind single-center trial was conducted in Iceland, for which 170 patients were recruited (Heidarsdottir et al., 2010). Patients were started 5-7 days preoperatively either on two soft capsules daily, totaling either $1240 \mathrm{mg}$ of EPA and $1000 \mathrm{mg}$ DHA as ethyl-esters (84 patients), or olive oil as a placebo (86 patients). Sample size was calculated based on an expected incidence of postoperative AF of $40 \%$ in the placebo group, a reduction to $20 \%$ by the intervention, and the usual assumptions. At study end, 83 patients were evaluated in the intervention 
group, and 85 in the placebo group. Onset of $\mathrm{AF}$ of a duration of $>5 \mathrm{~min}$ was assessed by continuous electrographic monitoring. Treatment duration was 2-28 days, and postoperative AF was observed in $54.2 \%$ in the intervention group and in $54.1 \%$ of the placebo group (n.s.), although EPA and DHA were significantly higher in plasma phospholipids in the intervention group than in the control group $(p<0.01)$. Other outcomes were not significantly different, including safety parameters. The authors concluded that "There is no evidence for a beneficial effect of treatment with $n-3$ PUFA on the occurrence of postoperative AF in patients undergoing open heart surgery" (Heidarsdottir et al., 2010). In a substudy in the 140 patients undergoing coronary bypass grafting, it was found that EPA and DHA might prevent AF in patients with low plasma phospholipid baseline levels of EPA and DHA, but might be harmful in those with high levels (Skuladottir et al., 2011). These findings, however, were not very robust.

In an observatory study in 530 Italian patients undergoing cardiac surgery, preoperative intake of $860 \mathrm{mg}$ EPA + DHA ethyl-ester for a median of 5 days by $16 \%$ of the population was associated with a decreased incidence of early, but not late AF after cardiac surgery (Mariscalco et al., 2010).

In Australia, for a single-center randomized controlled, doubleblind study, 200 patients were randomized after a coronary bypass or cardiac valve operation (Farquharson et al., 2011). A fish oil, providing a daily dose of $4.5 \mathrm{~g} \mathrm{EPA}+\mathrm{DHA}$ was compared to another oil, largely containing oleic acid, in the form of $15 \mathrm{ml}$ liquid, which was to be taken from 3 weeks pre-operatively on. The primary outcome was occurrence of sustained AF/atrial flutter (duration $\geq 10 \mathrm{~min}$ or requiring intervention) during the first 6 postoperative days. Sample size was calculated based on an expected incidence of postoperative AF in $42 \%$ of patients, a $53 \%$ relative risk reduction and the usual assumptions. An intentionto-treat analysis was performed in the 194 participants operated upon. Onset of AF was assessed based on continuous electrocardiographic monitoring. In the intervention group, EPA and DHA increased in red cells from $5.91 \pm 1.10$ to $8.80 \pm 1.73 \%(p<0.05)$, but remained stable in the control group. AF occurred in 47 of $97(48 \%)$ in the control group and 36 of 97 (37\%) in the fish oil group $(p=0.11)$. Time to AF was non-significantly longer $(p=0.06)$, and stay in the ICU significantly shorter $(p=0.005)$ in the intervention group, adverse events were evenly distributed. The authors concluded that "dietary fish oil did not result in a significant decrease in the incidence of postsurgical AF," but noted the significant decrease in time spent in the intensive care unit (Farquharson et al., 2011).

A systematic review on trials on prevention of new-onset postoperative AF that did not include the Australian trial, noted nonsignificant reductions in the occurrence of postoperative AF of 22\% (OR, 95\% CI 0.48-1.27), and called for larger trials (Liu et al., 2011). One larger trial is currently ongoing (Mozaffarian et al., 2011b). Whether new-onset postoperative AF can be considered a model for new-onset of AF without a prior cardiac operation remains a matter of debate. However, as demonstrated by the trials discussed above, new-onset postoperative AF is a common and unresolved problem after cardiac surgery, and any form of effective low-risk prevention would be welcome.

\section{New-onset of $A F$}

In an observatory study, based on an Italian population of 2,239,205 subjects, using hospital discharge records, prescription databases, and the civil registry, patients discharged after an acute myocardial infarction free of AF, were monitored for 360 days for death from any cause and for new-onset AF (Macchia et al., 2008). Those prescribed EPA + DHA had a relative risk for hospitalization for AF of 0.19 (hazard ratio, 95\% CI 0.07-0.51], and for all-cause mortality of 0.15 (hazard ratio of 95\% CI $0.05-0.46$ ). Another observatory study in 2174 Finnish subjects, followed for 17.7 years, 240 developed new AF (Virtanen et al., 2009). The quartile with the highest serum DHA had a relative risk for new AF of 0.64 (hazard ratio, 95\% CI 0.42-0.92). A publication from the Women's Health Initiative saw no relation between fish intake and new-onset of AF in 44,720 participants, subjected to electrocardiograms after 3 and 6 years (Berry et al., 2010). In contrast, in an Italian study, the red cells of 40 patients with AF/atrial flutter contained a higher percentage of EPA and DHA than those of 53 controls (Viviani Anselmi et al., 2010). In keeping, a report from the Framingham study saw an increased risk for incident AF with $>4$ servings of dark fish (Shen et al., 2011). Clearly, to define the role of EPA and DHA in prevention of new-onset of AF, a large scale clinical trial is required. The author is part of a world-wide effort to make such a trial possible.

\section{Prevention of recurrent AF}

In an observational study on 1500 patients undergoing catheter ablation, 285 were treated with omega-3 fatty acids (Patel et al., 2010). Of those 129 were matched to 129 controls. Of the patients treated with omega-3 fatty acids, $35(27.1 \%)$ had early recurrence vs. $57(44.1 \%)$ in the control group $(p<0.0001)$. Less procedural failures were observed in the treated group $(p<0.003$; Patel et al., 2010).

A multi-center randomized controlled double-blind 24-week trial was conducted in 663 US outpatient participants with confirmed symptomatic paroxysmal $(n=542)$ or persistent $(n=121)$ AF (Kowey et al., 2010). Participants received either four $1 \mathrm{~g}$ capsules per day of an $85 \%$ fish oil concentrate in the form of an ethyl-ester (332 patients), or identical capsules containing olive oil as a placebo (331 patients). The primary end point was a first symptomatic recurrence of AF in participants with paroxysmal AF. Study size was based on a $32 \%$ risk reduction, and the trial was to be stopped at 295 primary endpoints (Pratt et al., 2009). Five hundred eighty-four participants completed the study. Data were analyzed according to modified intention-to-treat. Although EPA and DHA increased in plasma, no differences were noted in the primary endpoint: in participants with paroxysmal AF (hazard ratio, 1.15 ; 95\% CI $0.90-1.46 ; p=0.26)$, or in participants with persistent AF (HR, 1.64; 95\% CI 0.92-2.92; $p=0.09$ ), or both combined (HR, 1.22; 95\% CI 0.98-1.52; $p=0.08$ ). Secondary endpoints also did not differ. Heart rate during the recurrent AF was lower in the group with EPA + DHA by 6.88 bpm than in the control group. Untoward effects were evenly distributed. The authors concluded that "Among participants with paroxysmal AF, 24-week treatment with prescription omega- 3 compared with placebo did not reduce recurrent AF over 6 months" (Pratt et al., 2009; Kowey et al., 2010). 
Whether three $1 \mathrm{~g}$ capsules of an 85\% EPA + DHA ethylester would prevent recurrence of AF after electric cardioversion was tested in a multi-center randomized controlled doubleblind 6 month trial in Italy vs. an olive oil placebo (Bianconi et al., 2011). Patients were included, if AF had persisted $>1$ month. The primary endpoint was the percentage of recurrence, and study sized was based on a recurrence of $50 \%$ in control patients, and $35 \%$ in intervention patients, and the usual assumptions. Into the intervention group, 111 patients were recruited, and 103 into the placebo group. Included into the analysis were 104 patients (intervention) and 100 (placebo). EPA and DHA increased significantly in the intervention group, but remained stable in the control group. Sinus rhythm was restored, either spontaneously or after electric cardioversion, in 187 patients $(91.7 \%)$; 95 patients $(91.4 \%)$ on EPA + DHA, and 92 patients $(92.0 \%)$ on placebo $(p=$ n.s.). AF relapsed in 56 $(58.9 \%)$ on EPA + DHA and in $47(51.1 \%)$ of the placebo patients $(p=$ n.s.). The mean time to AF recurrence was $83+8$ days in the EPA + DHA group and $106+9$ days in the placebo group $(p=$ n.s.). Adverse events were evenly distributed. The authors concluded that their "results do not support the hypothesis that in patients undergoing electric cardioversion of chronic persistent AF, supplementation with PUFAs in addition to the usual anti-arrhythmic treatment reduces recurrent AF" (Bianconi et al., 2011).

Very recently, a similar randomized controlled double-blind single-center trial was published from Italy (Nodari et al., 2011). Two $1 \mathrm{~g}$ capsules contained either a 85\% EPA + DHA ethyl-ester or an olive oil placebo. Patients with persistent AF were included, if they had at least one relapse after a previous cardioversion, had an atrial size of $>60 \mathrm{~mm}$ in a echocardiogram, but all were treated with amiodarone and an inhibitor of the renin-angiotensin system. Patients were pre-treated for 4 weeks before electric cardioversion. The primary endpoint was the probability of AF after 1 year. Study size was estimated based on a relapse rate of $50 \%$, a $20 \%$ reduction of that rate by the intervention and the usual assumptions. Into the intervention group, 102, into the placebo group 103 patients were recruited, and in both groups 94 patients completed the study, but the analysis was intention-to-treat. The probability of maintenance of sinus rhythm was higher in the intervention group than in the placebo group (HR 0.62, 95\% CI $0.52-0.72, p<0.0001)$. Adverse effects were minor in both groups. The authors concluded that EPA + DHA may exert beneficial effects in the prevention of AF recurrence," and state that "Further studies are needed to confirm and expand our findings" (Nodari et al., 2011).

During writing of this review, results of an open, uncontrolled single-center intervention were reported (Watanabe et al., 2011). For 6 months, patients with paroxysmal AF were on either propafenone or flecainide, and for the subsequent 6 months $1.8 \mathrm{~g}$ EPA-ethyl-ester/day was added. While 51 patients commenced the study, one patient developed a skin rash after 2 days of EPA, and thus 50 patients were evaluated. An estimation of study size was not reported. AF was assessed by self-recorded electrocardiograms. The primary endpoint, AF burden, defined as the number of days of AF per month, was not different before and after the intervention with EPA (Watanabe et al., 2011).
The systematic review already mentioned additionally included other trials on recurrent AF published in abstract form, and found an overall reduction of recurrent AF of $17 \%$ (OR, 95\%CO 0.481.45; Liu et al., 2011). Taken together, epidemiologic findings and the results of the intervention trials reported thus far make prevention of recurrent AF after electric cardioversion with EPA + DHA a promising target for further research. A number of such studies are currently ongoing (c.f. clinicaltrials.gov).

\section{VENTRICULAR ARRHYTHMIAS Intermediate parameters}

In an epidemiologic study in 260 patients with acute myocardial infarction, intake of omega-3 fatty acids was found to correlate inversely with premature ventricular beats (Smith et al., 2009). In an epidemiologic study in 707 Alaskan natives, a significant negative association between heart rate and the omega-3 Index was seen (Ebbesson et al., 2010). In two small studies, VT's were found to be less inducible in the electrophysiology laboratory after a 6week intake of $900 \mathrm{mg}$ EPA + DHA/day, or acute infusion of $3.9 \mathrm{~g}$ EPA + DHA (Metcalf et al., 2008; Madsen et al., 2010).

\section{Studies in carriers of an implanted cardioverter-defibrillator}

A meta-analysis on the three trials evaluating the effects of EPA and DHA in a total of 1148 carriers of an implanted cardioverterdefibrillator (ICD) concluded that "These findings do not support a protective effect of omega-3 PUFAs from fish oil on cardiac arrhythmia in all patients with an ICD," and felt the same to be true for all subgroups (Brouwer et al., 2010). A retrospective analysis of the 566 participants carrying an ICD in the GISSI-Heart failure trial found a similar result, but concluded that "The results of this study, though not statistically significant, support prior evidences of an anti-arrhythmic effect of $n-3$ PUFA in patients with ICD" (Finzi et al., 2011). Of note, a relatively small study in 102 German carriers of an ICD found that the higher the content of red blood cells in EPA + DHA, the higher the likelihood of an action of the ICD (Wilhelm et al., 2008). Interestingly, the authors noted that "These arrhythmias (VT's) were more often monomorphic and had a longer average cycle length, suggesting reentrant mechanism. These arrhythmias are not necessarily life-threatening." In a randomized controlled trial in 44 carriers of an ICD, among other parameters, microvolt T-wave analysis improved, heart rate variability increased and the heart rate of non-sustained VT decreased (Nodari et al., 2009) Taken together, the results of the ICD-studies support the need to differentiate the cause of the action of the ICD (VT vs. VF), and the action of the ICD (anti-tachycardia pacing vs. shock) in such studies, as discussed earlier (von Schacky, 2008) to get a clearer picture of the effects of EPA and DHA in carriers of an ICD.

\section{Sudden cardiac death}

In an epidemiologic study, long-term fish consumption was associated with a lower risk for SCD (Streppel et al., 2008). This is in keeping with the observation that a low omega-3 index increased the risk of ventricular fibrillation during the acute ischemic phase of a myocardial infarction (Aarsetoey et al., 2008), and the observation that a low omega-3 index was found to be associated with SCD (Aarsetoey et al., 2011). Of note, a 1\% increase of the omega-3 
index was associated with a $58 \%(95 \%$ CI $0.25-0.76 \%)$ reduction in risk of VF during the acute phase of a myocardial infarction (Aarsetoey et al., 2011).

\section{Intervention trials with clinical endpoints}

Late 2008, a systematic review of randomized controlled trials of fish oil as dietary supplements in humans found a non-significant reduction in SCD (odds ratio, OR0.81, 95\% CI 0.52-1.25), but a significant reduction in death from cardiac causes (OR0.80, 95\% CI 0.69-0.92; León et al., 2008). SCD is an elusive endpoint, since it occurs only in $1.4 \%$ of a population after a myocardial infarction (Marchioli et al., 2002), mandating large study sizes or metaanalyses of large studies for any intervention to demonstrate an effect. For that reason, SCD is rarely selected as a primary endpoint of an intervention study. Combining important clinical events is the preferred approach.

An example was the Heart Failure trial by the Italian GISSIgroup (Gissi-HF Investigators et al., 2008) Patients with chronic heart failure of New York Heart Association class II-IV were recruited, and randomly assigned to $850 \mathrm{mg}$ EPA + DHA as ethylester daily $(n=3494)$ or to a matching placebo $(n=3481)$. The trial had two co-primary endpoints: time to death and time to death or admission to hospital for cardiovascular reasons. Study size was estimated based on a $15 \%$ relative reduction of the expected absolute mortality rate of $25 \%$ during 3 years and $90 \%$ power and a two-sided significance of 0.045 . Analysis was by intention-to-treat. EPA + DHA were as safe and as tolerable as placebo. After 3.9 years, time to death was reduced by $9 \%$ [adjusted hazard ratio (HR) $0.91,95.5 \%$ CI $0.833-0.998, p=0.041$ ], while time to death or admission to hospital for cardiovascular reasons was reduced by $8 \%$ (adjusted HR 0.92, 99\% CI 0.849.0.999, $p=0.009)$. Adjustments were predefined and due to baseline inequalities. In the intervention group, 274 participants $(7.8 \%)$ died a presumably arrhythmic death, in contrast to 304 participants $(8.7 \%)$ in the placebo group (adjusted HR 0.88, 95\% CI $0 \cdot 75-1 \cdot 04, p=0.141)$. SCD occurred in 307 (9\%) patients allocated to $n-3$ PUFA and 325 (9\%) in the placebo group (adjusted HR $0.93,95 \%$ CI $0.79-1.08, p=0.333)$. The authors concluded that " $n-3$ PUFA can provide a small beneficial advantage in terms of mortality and admission to hospital for cardiovascular reasons in patients with heart failure" (Gissi-HF Investigators et al., 2008).

The Alpha-Omega Trial was a multi-center, double-blind, placebo-controlled trial in 4837 patients after a myocardial infarction (Geleijnse et al., 2010; Kromhout et al., 2010). Patients were randomly assigned to receive four trial margarines: a margarine supplemented with $400 \mathrm{mg}$ of EPA + DHA, a margarine supplemented with $2 \mathrm{~g}$ of ALA, a margarine supplemented with both, or a placebo margarine. The primary end point was a combination of fatal and non-fatal cardiovascular events and cardiac interventions, but SCD was not specifically followed. Study size estimation was initially based on a CHD mortality of $4 \%$ per year, and the usual assumptions, but had to be adjusted because of a lower mortality observed. Adjustment led to the combined endpoint just mentioned. Analysis was by intention-o-treat. Adverse events were evenly distributed among the four groups. None of the interventions reduced the primary endpoint. The authors concluded that
"Low-dose supplementation with EPA-DHA or ALA did not significantly reduce the rate of major cardiovascular events among patients who had had a myocardial infarction." Reasons for the neutral result discussed by the authors were specifics of the study population, concomitant pharmacologic treatment, and the lowdose given (Kromhout et al., 2010). Elsewhere, a relatively high background intake of EPA + DHA was discussed (Mozaffarian and $\mathrm{Wu}, 2011)$. More recently, the authors of the Alpha-Omega Trial reported a protective effect against ventricular arrhythmiarelated events in the subgroup of post-MI patients with diabetes (Kromhout et al., 2011).

At least in the field of omega-3 fatty acids, the only trial ambitiously using SCD as a primary endpoint was "OMEGA," a randomized, placebo-controlled, double-blind, multi-center trial comparing $1 \mathrm{~g}$ /day EPA + DHA as an ethyl-ester to an olive oil placebo for 1 year in 3851 German patients shortly after a myocardial infarction (Rauch et al., 2010). Study size was estimated based on previous registry data with SCD projected to occur in $1.9 \%$ in the group treated with omega-3 acid ethyl-esters 90 and $3.5 \%$ in the placebo group, and alpha of $2.5 \%$ and a power of $80 \%$ (Rauch et al., 2006). Primary analysis was by intention-to-treat, and SCD occurred in $1.5 \%$ of both verum and placebo groups, with other cardiovascular events also evenly distributed. As is, OMEGA had a statistical power of $44 \%$ to detect the assumed reduction in SCD. This power obviates any conclusion on the effect of EPA + DHA, because it remains unclear, whether the intervention tested was ineffective or the study size was too small. The authors discussed an unexpected low rate of SCD, cross-contamination by in increase in fish consumption, and improvements in drug therapy as reasons for their results. The authors concluded that "Guideline-adjusted treatment of acute myocardial infarction results in a low rate of SCD and other clinical events within 1 year of follow-up, which could not be shown to be further reduced by the application of omega-3 fatty acids." As mentioned, the power of the study does not permit conclusions with regard to the therapeutic effect of $\mathrm{EPA}+\mathrm{DHA}$. Moreover, in GISSI-P, in the first year after a myocardial infarction, the incidence of SCD in the control population was $1.4 \%$, basically identical to the incidence observed in OMEGA (Marchioli et al., 2002). In GISSI-P, a highly comparable study population participated, and treatment conforming current guidelines was less frequently applied. Therefore, the conclusion of the authors of OMEGA is not only scientifically unsound, but also not supported by the data presented. Strangely enough, the accompanying editorial reiterated the conclusions of OMEGA (Eckel, 2010).

The French SuFOL.OM3 trial was a randomized double-blind multi-center trial, and recruited 2501 participants with a history of myocardial infarction, unstable angina, or ischemic stroke (Galan et al., 2010). In a factorial design, $600 \mathrm{mg}$ EPA + DHA ethyl-ester was compared to vitamins, a combination of the two, or placebo. The primary endpoint was the first major cardiovascular event (e.g., non-fatal and fatal myocardial infarction, stroke, SCD, and others). Study size was based on an annual event rate of 0.087 , a $10 \%$ relative reduction by one intervention ( $19 \%$ by two), a power of $90 \%$, and a two-tailed $\alpha$ of 0.05 . In the 4.7 -year follow-up period, an event occurred in $6.3 \%$ of participants, with no statistically significant differences between groups. The authors discussed 
low-dose and low statistical power due to a lower than expected event rate as explanations for the neutral results. The authors concluded that "the study does not support the routine use of dietary supplements containing B vitamins or omega-3 fatty acids for prevention of cardiovascular disease" "after the acute phase of the initial event." Again, the power of the study does not permit conclusions with regard to the therapeutic effect of EPA + DHA, because of lack of sufficient statistical power.

\section{THE OMEGA-3 INDEX PERSPECTIVE}

The omega-3 index was defined as the percentage of EPA + DHA in red cells, as determined with a highly standardized analytical method, currently installed in a few laboratories around the world (Harris and von Schacky, 2004). While mean levels of the omega3 index differ from population to population, mean levels had a statistically normal distribution in all populations studied so far (von Schacky, 2011). Therefore, in any population, some individuals have relatively high, and some have relatively low levels, while most are in between. The omega-3 index reflects tissue levels of EPA + DHA, e.g., of the heart (von Schacky, 2011). A low omega-3 index is a strong predictor of future adverse cardiovascular events (von Schacky, 2011).

Using the omega-3 index to answer the question whether $\mathrm{EPA}+\mathrm{DHA}$ are anti- or pro-arrhythmic provides a clearer picture than the one provided thus far. In Japan, the mean omega-3 index was found to be $9.58 \%$ in unselected persons, and the incidence of SCD in the general population 7.8/100,000 person years, while in Western countries, the mean omega- 3 index is frequently among 5\%, and the incidence of SCD in the general population is $150 / 100,000$ person years (von Schacky, 2010). In two case-control studies on SCD in the US, levels of omega-3 fatty acids in red cells or whole blood were inversely related to risk for SCD, and a 10fold difference in risk was reported (von Schacky, 2010). Thus, a high omega-3 Index, e.g., 8-11\%, is associated with a low-risk for SCD, and risk appears to increase with decreasing values of the omega-3 index.

Experimental evidence indicates that acute increases in $\mathrm{EPA}+\mathrm{DHA}$ concentrations do not have a further anti-arrhythmic effect in tissues already replete with them (Den Ruijter et al., 2010). Therefore, it is unlikely that an anti-arrhythmic effect can be demonstrated in persons or populations with a high omega-3 index, like in Japan. In keeping, in a large randomized intervention study in persons at elevated risk for cardiovascular disease in Japan (20\% of whom had established cardiovascular disease), $1.8 \mathrm{~g} \mathrm{EPA} /$ day did not reduce SCD (Yokoyama et al., 2007). Of note, the incidence of SCD in JELIS was 40/100,000, substantially lower than in the general population in Western countries, as mentioned above (von Schacky, 2010). However, acute increases in EPA + DHA, e.g., by infusion or after a 6-week dietary intervention reduced inducibility of ventricular tachycardias, but only in subjects with low levels (Schrepf et al., 2004; Metcalf et al., 2008; Madsen et al., 2010). Although the latter studies were small and short, current evidence indicates that acute increases of EPA + DHA levels by infusion or a short-term dietary intervention can reduce the probability of ventricular arrhythmias in those with suboptimal levels, but that high tissue levels, reflected by a high omega-3 index, are protective.
A lower omega-3 index also makes other adverse outcomes more likely than a higher omega-3 index: Among the outcomes are ventricular fibrillation during a myocardial infarction (Aarsetoey et al., 2011), myocardial infarctions (Block et al., 2008; Park et al., 2009), mortality after a myocardial infarction (Pottala et al., 2010), and many more reviewed elsewhere (von Schacky, 2011). Supporting evidence is provided by plasma measurements of EPA + DHA (e.g., Mozaffarian et al., 2011a).

The omega-3 index has a lower biological variability than plasma or whole blood EPA + DHA (Harris and Thomas, 2010). The level of the omega- 3 index is determined by many factors, among them catabolism of EPA + DHA, age, body mass index, and intake of EPA + DHA (von Schacky, 2011). Intake, however, explains $<16$ or $12 \%$ of the variability of EPA + DHA in the red cell membrane (Ebbesson et al., 2010; Sala-Vila et al., 2011). This may partly explain, why epidemiologic studies focusing on intake of $\mathrm{EPA}+\mathrm{DHA}$ provided less clear results than epidemiologic studies focusing on the omega-3 index (von Schacky, 2010). In the future, a more widespread use of the omega- 3 index in research projects will provide a clearer picture of associations between EPA + DHA and cardiovascular events. Already now, however, the omega-3 index fulfills important criteria of the US Preventive Services Task Force or the American Heart Association for new biomarkers for cardiovascular risk (Helfand et al., 2009; Hlatky et al., 2009):

1. Ease and reliability of measurement. The analytical methodology is standardized in three laboratories around the world, and conforms to the rules of Clinical Chemistry (e.g., plausibility checks, proficiency testing).

2. Risk predicted independent of conventional risk factors. This has been demonstrated for an American and a Korean population, and was evidenced by a larger area under the curve in comparison to the Framingham index (Park et al., 2009; Shearer et al., 2009).

3. Reclassification of persons at intermediate risk (Shearer et al., 2009).

4. Therapeutic consequence. In all populations studied so far, an increase in intake of EPA + DHA increased the mean omega3 index. In meta-analyses, increased intake of EPA + DHA resulted in decreased occurrence of major cardiovascular events (e.g., León et al., 2008; Mozaffarian and Wu, 2011). Whether an omega-3 index based supplementation with EPA + DHA is superior to the current untargeted use of EPA + DHA remains to be formally demonstrated, however.

\section{DISCUSSION}

Only recently, bioavailability problems of preparations of EPA + DHA have surfaced. Unfortunately, while ethyl-esters have been used in most intervention trials, ethyl-esters are the least well absorbed chemical form of omega-3 fatty acids, and absorption depends on the fat content of the meal eaten with intake (Dyerberg et al., 2010; Neubronner et al., 2011). A lower bioavailability translates into a lower biological activity (Schuchardt et al., 2011). Moreover, large differences exist in absorption of EPA + DHA from individual to individual, even if an identical dose of a chemical form is taken in an identical matrix, in this case $940 \mathrm{mg}$ $\mathrm{EPA}+\mathrm{DHA}$ from salmon oil (triglyceride) in $200 \mathrm{ml}$ of a drink 
(Köhler et al., 2010). Both phenomena impact negatively on the differentiation between intervention and control groups in terms of dose of EPA + DHA absorbed.

Moreover, in all intervention trials mentioned, participants were recruited irrespective of their baseline levels of EPA + DHA. Participants with a high omega- 3 index at baseline are not likely to develop a cardiovascular event during a trial. In addition, levels of $\mathrm{EPA}+\mathrm{DHA}$ achieved in intervention and control groups during the study will overlap in a substantial portion of study participants, again negatively impacting on the differentiation between intervention and control groups in terms of levels of EPA + DHA achieved. Jointly, the two effects just mentioned produce a tendency toward neutrals results of clinical trials with EPA + DHA. In the future, recruiting study participants with a low baseline omega3 index, and treating to a target omega-3 index (e.g., 8-11\%) will make intervention trials with EPA + DHA more efficient. Very efficient trials are needed to demonstrate effects of any intervention on rare endpoints, like SCD or new-onset AF.

Pro-arrhythmic effects have not been seen in any intervention trial with clinical endpoints, rather arrhythmic events were either reduced or not significantly altered (Marchioli et al., 2002; GissiHF Investigators et al., 2008; León et al., 2008; Galan et al., 2010; Kromhout et al., 2010; Rauch et al., 2010; Mozaffarian and Wu, 2011). The same phenomenon has been seen in the animal studies reviewed above. This is in keeping with all but one epidemiologic study reporting slower VT's the higher the red cell content of EPA + DHA (Wilhelm et al., 2008). Thus, the data from epidemiologic and intervention studies are compatible with the speculation that EPA + DHA inhibit degeneration of non-fatal VT into fatal VF. A re-analysis of the original data obtained in the three intervention trials in carriers of an ICD would be a first step toward substantiating this speculation.

Currently, it is unclear, whether the anti-arrhythmic effect of $\mathrm{EPA}+\mathrm{DHA}$ is restricted to arrhythmias associated with ischemia or not. The data reported from the large clinical trials do not answer this question. The three small studies on inducibility of VT's in the electrophysiology laboratory argue in favor of an effect in the absence of ischemia (Schrepf et al., 2004; Metcalf et al., 2008; Madsen et al., 2010), as do results from studies using intermediate

\section{REFERENCES}

Aarsetoey, H., Aarsetoey, R., Lindner, T., Staines, H., Harris, W. S., and Nilsen, D. W. (2011). Low levels of the omega-3 index are associated with sudden cardiac arrest and remain stable in survivors in the subacute phase. Lipids 46, 151-161.

Aarsetoey, H., Pönitz, V., Nilsen, O. B., Grundt, H., Harris, W. S., and Nilsen, D. W. (2008). Low levels of cellular omega-3 increase the risk of ventricular fibrillation during the acute ischaemic phase of a myocardial infarction. Resuscitation 78, 258-264.

Abdukeyum, G. G., Owen, A. J., and McLennan, P. L. (2008). Dietary (n-3) long-chain polyunsaturated fatty acids inhibit ischemia and

or surrogate parameters, such as heart rate, heart rate variability, or rate of VT's (discussed above). The observation from Norway that an $1 \%$ increase in the omega- 3 index was associated with a $58 \%$ reduction in risk of VF during the acute phase of a myocardial infarction (Aarsetoey et al., 2011), supports the notion that the anti-arrhythmic effect of EPA + DHA becomes specifically important in the presence of ischemia. Based on current evidence, this question cannot be resolved with certainty, however (Raitt, 2009).

\section{CONCLUSION}

Taken together, there is no evidence that EPA + DHA are arrhythmic at the atrial level, i.e., that EPA + DHA propagate AF. Rather, intervention trials so far indicate that there might be a small preventive effect that needs to be investigated in larger and/or more efficient trials than conducted so far. This is true for postoperative AF, recurrent AF and new-onset AF. On the ventricular level, epidemiologic studies indicate a possible anti-arrhythmic effect, possibly by slowing VT, thus possibly preventing progression to VF. Results of trials on intermediate endpoints in carriers of an ICD were inconclusive, possibly because of indiscriminate combination of endpoints. SCD is a rare event. Unfortunately, the only intervention trial to study SCD as a primary endpoint was inadequately powered, obviating a conclusion on the preventive effect of EPA + DHA on SCD. Other trials used combinations of endpoints, usually including an arrhythmic endpoint and in no trial, a pro-arrhythmic effect was found. Due to problems with study power in another trial, and the possibility of inadequate dosing in yet another, the anti-arrhythmic effect of EPA + DHA was recently demonstrated in only one trial in patients with congestive heart failure. All trials thus far suffer from a tendency toward a neutral result, since study participants were recruited irrespective of their baseline omega-3 index. Rather than indiscriminately recruiting study participants, use of a low omega-3 index as an inclusion criterion will make more efficient intervention trials possible, and will lead to a clearer delineation of mechanisms of action. Use of the omega-3 index provides a more targeted approach toward defining the impact of EPA + DHA and/or their derivatives on cardiac rhythm.

atrial fibrillation (from the Women's Health Initiative). Am. J. Cardiol. 105, 844-848.

Bianconi, L., Calò, L., Mennuni, M. Santini, L., Morosetti, P., Azzolini, P., Barbato, G., Biscione, F., Romano, P. and Santini, M. (2011). n-3 polyunsaturated fatty acids for the prevention of arrhythmia recurrence after electrical cardioversion of chronic persistent atrial fibrillation: a randomized, double-blind, multicentre study. Europace 13, 174-181.

Billman, G. E., and Harris, W. S. (2011). Effect of dietary omega-3 fatty acids on the heart rate and the heart rate variability responses to myocardial ischemia or submaximal exercise. Am. J. Physiol. Heart Circ. Physiol. 300, H2288-H2299.
Billman, G. E., Harris, W. S., Carnes, C. A., Adamson, P. B., Vanoli, E., and Schwartz, P. J. (2012). Dietary omega-3 fatty acids and susceptibility to ventricular fibrillation: Lack of protection and A proarrhythmic effect. Circ. Arrhythm. Electrophysiol. PMID: 22333345. [Epub ahead of print].

Billman, G. E., Nishijima, Y., Belevych, A. E., Terentyev, D., Xu, Y., Haizlip, K. M., Monasky, M. M., Hiranandani, N., Harris, W. S., Gyorke, S., Carnes, C. A., and Janssen, P. M. (2010). Effects of dietary omega-3 fatty acids on ventricular function in dogs with healed myocardial infarctions: in vivo and in vitro studies. Am. J. Physiol. Heart Circ. Physiol. 298, H1219-H1228. 
Block, R. C., Harris, W. S., Reid, K. J., Sands, S. A., and Spertus, J. A. (2008). EPA and DHA in blood cell membranes from acute coronary syndrome patients and controls. Atherosclerosis 197, 821-828.

Brouwer, I. A., Raitt, M. H., Dullemeijer, C., Kraemer, D. F., Zock, P. L., Morris, C., Katan, M. B., Connor, W. E., Camm, J. A., Schouten, E. G., and McAnulty, J. (2010). Effect of fish oil on ventricular tachyarrhythmia in three studies in patients with implantable cardioverter defibrillators. Eur. Heart J. 30, 820-826.

Calò, L., Bianconi, L., Colivicchi, F., Lamberti, F., Loricchio, M. L., de Ruvo, E., Meo, A., Pandozi, C., Staibano, M., and Santini, M. (2005). $\mathrm{N}-3$ fatty acids for the prevention of atrial fibrillation after coronary artery bypass surgery: a randomized, controlled trial. J. Am. Coll. Cardiol. 45, 1723-1728.

De Caterina, R. (2011). N-3 fatty acids in cardiovascular disease. N. Engl. J. Med. 364, 2439-2450.

Den Ruijter, H. M., Berecki, G., Verkerk, A. O., Bakker, D., Baartscheer, A., Schumacher, C. A., Belterman, C. N., de Jonge, N., Fiolet, J. W., Brouwer, I. A., and Coronel, R. (2008). Acute administration of fish oil inhibits triggered activity in isolated myocytes from rabbits and patients with heart failure. Circulation 117, 536-544.

Den Ruijter, H. M., Verkerk, A. O., and Coronel, R. (2010). Incorporated fish oil fatty acids prevent action potential shortening induced by circulating fish oil fatty acids. Front. Physiol. 1:149. doi:10.3389/fphys.2010.00149

Dujardin, K. S., Dumotier, B., David, M., Guizy, M., Valenzuela, C., and Hondeghem, L. M. (2008). Ultrafast sodium channel block by dietary fish oil prevents dofetilide-induced ventricular arrhythmias in rabbit hearts. Am. J. Physiol. Heart Circ. Physiol. 295, H1414-H1421.

Dyerberg, J., Madsen, P., Møller, J. M., Aardestrup, I., and Schmidt, E. B. (2010). Bioavailability of marine n-3 fatty acid formulations. Prostaglandins Leukot. Essent. Fatty Acids 83, 137-141.

Ebbesson, S. O., Devereux, R. B., Cole, S., Ebbesson, L. O., Fabsitz, R. R., Haack, K., Harris, W. S., Howard, W. J., Laston, S., Lopez-Alvarenga, J. C., MacCluer, J. W., Okin, P. M., Tejero, M. E., Voruganti, V. S., Wenger, C. R., Howard, B. V., and Comuzzie, A. G. (2010). Heart rate is associated with red blood cell fatty acid concentration: the Genetics of Coronary
Artery Disease in Alaska Natives (GOCADAN) Study. Am. Heart J. 159, 1020-1025.

Eckel, R. H. (2010). The fish oil story remains fishy. Circulation 122 , 2110-2112.

Falck, J. R., Wallukat, G., Puli, N., Goli, M., Arnold, C., Konkel, A., Rothe, M., Fischer, R., Müller, D. N., and Schunck, W. H. (2011). 17(R),18(S)-epoxyeicosatetraenoic acid, a potent eicosapentaenoic acid (EPA) derived regulator of cardiomyocyte contraction: structure-activity relationships and stable analogues. J. Med. Chem. 54, 4109-4118.

Farquharson, A. L., Metcalf, R. G., Sanders, P., Stuklis, R., Edwards, J. R., Gibson, R. A., Cleland, L. G., Sullivan, T. R., James, M. J., and Young, G. D. (2011). Effect of dietary fish oil on atrial fibrillation after cardiac surgery. Am. J. Cardiol. 108, 851-856.

Finzi, A. A., Latini, R., Barlera, S., Rossi, M. G., Ruggeri, A., Mezzani, A., Favero, C., Franzosi, M. G., Serra, D., Lucci, D., Bianchini, F., Bernasconi, R., Maggioni, A. P., Nicolosi, G., Porcu, M., Tognoni, G., Tavazzi, L., and Marchioli, R. (2011). Effects of $\mathrm{n}-3$ polyunsaturated fatty acids on malignant ventricular arrhythmias in patients with chronic heart failure and implantable cardioverterdefibrillators: a substudy of the Gruppo Italiano per lo Studio della Sopravvivenza nell'Insufficienza Cardiaca (GISSI-HF) trial. Am. Heart J. 161, 338-343.

Galan, P., Kesse-Guyot, E., Czernichow, S., Briancon, S., Blacher, J., Hercberg, S., and SU.FOL.OM3 Collaborative Group. (2010). Effects of B vitamins and omega 3 fatty acids on cardiovascular diseases: a randomised placebo controlled trial. BMJ 341, c6273.

Geleijnse, J. M., Giltay, E. J., Schouten, E. G., de Goede, J., Oude Griep, L. M., Teitsma-Jansen, A. M., Katan, M. B., and Kromhout, D. (2010). Alpha Omega Trial Group. Effect of low doses of n-3 fatty acids on cardiovascular diseases in 4,837 post-myocardial infarction patients: design and baseline characteristics of the Alpha Omega Trial. Am. Heart J. 159, 539-546.

Gissi-HF Investigators, Tavazzi, L., Maggioni, A. P., Marchioli, R., Barlera, S., Franzosi, M. G., Latini, R., Lucci, D., Nicolosi, G. L., Porcu, M., and Tognoni, G. (2008). Effect of $n-3$ polyunsaturated fatty acids in patients with chronic heart failure (the GISSI-HF trial): a randomised, double-blind, placebo-controlled trial. Lancet 372, 1223-1230.

Gronroos, N. N., and Alonso, A. (2010). Diet and risk of atrial fibrillation epidemiologic and clinical evidence. Circ. J. 74, 2029-2038.

Harris, W. S., and Thomas, R. M. (2010). Biological variability of blood omega-3 biomarkers. Clin. Biochem. 43, 338-340.

Harris, W. S., and von Schacky, C. (2004). The omega-3 index: a new risk factor for death from coronary heart disease? Prev. Med. 39, 212-220.

Heidarsdottir, R., Arnar, D. O., Skuladottir, G. V., Torfason, B., Edvardsson, V., Gottskalksson, G., Palsson, R., and Indridason, O. S. (2010). Does treatment with n-3 polyunsaturated fatty acids prevent atrial fibrillation after open heart surgery? Europace 12, 356-363.

Heidt, M. C., Vician, M., Stracke, S. K., Stadlbauer, T., Grebe, M. T., Boening, A., Vogt, P. R., and Erdogan, A. (2009). Beneficial effects of intravenously administered N-3 fatty acids for the prevention of atrial fibrillation after coronary artery bypass surgery: a prospective randomized study. Thorac. Cardiovasc. Surg. 57, 276-280.

Helfand, M., Buckley, D. I., Freeman, M., Fu, R., Rogers, K., Fleming, C., and Humphrey, L. L. (2009). Emerging risk factors for coronary heart disease: a summary of systematic reviews conducted for the U.S. Preventive Services Task Force. Ann Intern. Med. 151, 496-507.

Hlatky, M. A., Greenland, P., Arnett, D. K., Ballantyne, C. M., Criqui, M. H., Elkind, M. S., Go, A. S., Harrell, F. E. Jr., Hong, Y., Howard, B. V., Howard, V. J., Hsue, P. Y., Kramer, C. M., McConnell, J. P., Normand, S. L., O’Donnell, C. J., Smith, S. C. Jr., and Wilson, P. W. (2009). American Heart Association expert panel on subclinical atherosclerotic diseases and emerging risk factors and the Stroke Council. Circulation 119, 2408-2416.

Huggins, C. E., Curl, C. L., Patel, R., McLennan, P. L., Theiss, M. L., Pedrazzini, T., Pepe, S., and Delbridge, L. M. (2009). Dietary fish oil is antihypertrophic but does not enhance postischemic myocardial function in female mice. Am. J. Physiol. Heart Circ. Physiol. 296, H957-H966.

Kitamura, K., Shibata, R., Tsuji, Y., Shimano, M., Inden, Y., and Murohara, T. (2011). Eicosapentaenoic acid prevents atrial fibrillation associated with heart failure in a rabbit model. Am. J. Physiol. Heart Circ. Physiol. 300, H1814-H1821.

Köhler, A., Bittner, D., Löw, A., and von Schacky, C. (2010). Effects of a convenience drink fortified with $\mathrm{n}$ 3 fatty acids on the n-3 index. $\mathrm{Br}$. J. Nutr. 104, 729-736.

Kowey, P. R., Reiffel, J. A., Ellenbogen, K. A., Naccarelli, G. V., and Pratt, C. M. (2010). Efficacy and safety of prescription omega- 3 fatty acids for the prevention of recurrent symptomatic atrial fibrillation: a randomized controlled trial. J. Am. Med. Assoc. 304, 2363-2372.

Kromhout, D., Geleijnse, J. M., de Goede, J., Oude Griep, L. M., Mulder, B. J., de Boer, M. J., Deckers, J. W., Boersma, E., Zock, P. L., and Giltay, E. J. (2011). n-3 fatty acids, ventricular arrhythmiarelated events, and fatal myocardial infarction in postmyocardial infarction patients with diabetes. Diabetes Care 34, 2515-2520.

Kromhout, D., Giltay, E. J., Geleijnse, J. M., and Alpha Omega Trial Group. (2010). N-3 fatty acids and cardiovascular events after myocardial infarction. N. Engl. J. Med. 363, 2015-2026.

Kumar, S., Sutherland, F., The, A. W., Heck, P. M., Lee, G., Garg, M. L., and Sparks, P. B. (2011a). Effects of chronic omega-3 polyunsaturated fatty acid supplementation on human pulmonary vein and left atrial electrophysiology in paroxysmal atrial fibrillation. Am. J. Cardiol. 108, 531-535.

Kumar, S., Sutherland, F., Rosso, R., The, A. W., Lee, G., Heck, P. M., Feldman, A., Medi, C., Watt, S., Garg, M. L., and Sparks, P. B. (2011b). Effects of chronic omega-3 polyunsaturated fatty acid supplementation on human atrial electrophysiology. Heart Rhythm 8, 562-568.

Kumar, S., Sutherland, F., Wheeler, M., Heck, P. M., Lee, G., The, A. W., Garg, M. L., Morgan, J. G., and Sparks, P. B. (2011c). Effects of chronic omega-3 polyunsaturated fatty acid supplementation on human atrial mechanical function after reversion of atrial arrhythmias to sinus rhythm: reversal of tachycardia-mediated atrial cardiomyopathy with fish oils. Heart Rhythm 8, 643-649.

León, H., Shibata, M. C., Sivakumaran, S., Dorgan, M., Chatterley, T., and Tsuyuki, R. T. (2008). Effect of fish oil on arrhythmias and mortality: systematic review. BMJ 337, a2931.

Liu, T., Korantzopoulos, P., Shehata, M., Li, G., Wang, X., and Kaul, S. (2011). Prevention of atrial fibrillation with omega-3 fatty acids: a meta-analysis 
of randomised clinical trials. Heart 97, 1034-1040.

Macchia, A., Monte, S., Pellegrini, F., Romero, M., Ferrante, D., Doval, H., D'Ettorre, A., Maggioni, A. P., and Tognoni, G. (2008). Omega-3 fatty acid supplementation reduces one-year risk of atrial fibrillation in patients hospitalized with myocardial infarction. Eur. J. Clin. Pharmacol. 64, 627-634.

Madsen, T., Christensen, J. H., Thøgersen, A. M., Schmidt, E. B., and Toft, E. (2010). Intravenous infusion of $n-3$ polyunsaturated fatty acids and inducibility of ventricular tachycardia in patients with implantable cardioverter defibrillator. Europace 12, 941-946.

Marchioli, R., Barzi, F., Bomba, E., Chieffo, C., Di Gregorio, D., Di Mascio, R., Franzosi, M. G., Geraci, E., Levantesi, G., Maggioni, A. P., Mantini, L., Marfisi, R. M., Mastrogiuseppe, G., Mininni, N., Nicolosi, G. L., Santini, M., Schweiger, C., Tavazzi, L., Tognoni, G., Tucci, C., Valagussa, F., and GISSI-Prevenzione Investigators. (2002). Early protection against sudden death by $n$ 3 polyunsaturated fatty acids after myocardial infarction. Time-course analysis of the results of the Gruppo Italiano per lo Studio della Sopravvivenza nell'Infarcto Miocardio (GISSI)-Prevenzione. Circulation 105, 1897-1903.

Mariscalco, G., Sarzi Braga, S., Banach, M., Borsani, P., Bruno, V. D., Napoleone, M., Vitale, C., Piffaretti, G., Pedretti, R. F., and Sala, A. (2010). Preoperative n-3 polyunsaturated fatty acids are associated with a decrease in the incidence of early atrial fibrillation following cardiac surgery. Angiology 61, 643-650.

Mayyas, F., Sakurai, S., Ram, R., Rennison, J. H., Hwang, E. S., Castel, L., Lovano, B., Brennan, M. L., Bibus, D., Lands, B., Barnard, J., Chung, M. K., and Van Wagoner, D. R. (2011). Dietary $\omega 3$ fatty acids modulate the substrate for post-operative atrial fibrillation in a canine cardiac surgery model. Cardiovasc. Res. 89, 852-861.

Metcalf, R. G., Sanders, P., James, M. J., Cleland, L. G., and Young, G. D. (2008). Effect of dietary n-3 polyunsaturated fatty acids on the inducibility of ventricular tachycardia in patients with ischemic cardiomyopathy. Am. J. Cardiol. 101, 758-761.

Mitasíková, M., Smidová, S., Macsaliová, A., Knezl, V., Dlugosová, K., Okruhlicová, L., Weismann, P., and Tribulová, N. (2008). Aged male and female spontaneously hypertensive rats benefit from n-3 polyunsaturated fatty acids supplementation. Physiol. Res. 57(Suppl. 2), S39-S48.

Mozaffarian, D., Lemaitre, E. N., King, I. B., Song, X., Spiegelman, D., Sacks, F. M., Rimm, E. B., and Siscovick, D. S. (2011a). Circulating long-chain $\omega-3$ fatty acids and incidence of congestive heart failure in older adults: the cardiovascular health study. a cohort study. Ann. Intern. Med. 155, 160-179.

Mozaffarian, D., Marchioli, R., Gardner, T., Ferrazzi, P., O'Gara, P., Latini, R., Libby, P., Lombardi, F., Macchia, A., Page, R., Santini, M., Tavazzi, L., and Tognoni, G. (2011b). The $\omega-3$ fatty acids for prevention of postoperative atrial fibrillation trial rationale and design. Am. Heart J. 162, 56-63.

Mozaffarian, D., and Wu, J. H. (2011). Omega- 3 fatty acids and cardiovascular disease: effects on risk factors, molecular pathways, and clinical events. J. Am. Coll. Cardiol. 58, 2047-2067.

Neubronner, J., Schuchardt, J. P., Kressel, G., Merkel, M., von Schacky, C., and Hahn, A. (2011). Enhanced increase of omega-3 index in response to long-term n-3 fatty acid supplementation from triacylglycerides versus ethyl esters. Eur. J. Clin. Nutr. 65, 247-254.

Nodari, S., Metra, M., Milesi, G., Manerba, A., Cesana, B. M., Gheorghiade, M., and Dei Cas, L. (2009). The role of $n-3$ PUFAs in preventing the arrhythmic risk in patients with idiopathic dilated cardiomyopathy. Cardiovasc. Drugs Ther. 23, 5-15.

Nodari, S., Triggiani, M., Campia, U., Manerba, A., Milesi, G., Cesana, B. M., Gheorghiade, M., and Dei Cas, L. (2011). n-3 polyunsaturated fatty acids in the prevention of atrial fibrillation recurrences after electrical cardioversion: a prospective, randomized study. Circulation 124, 1100-1106

Park, Y., Lim, J., Lee, J., and Kim, S. G. (2009). Erythrocyte fatty acid profiles can predict acute non-fatal myocardial infarction. Br. J. Nutr. 102, 1355-1356.

Patel, D., Shaheen, M., Venkatraman, P., Armaganijan, L., Sanchez, J. E., Horton, R. P., Di Biase, L., Mohanty, P., Canby, R., Bailey, S. M., Burkhardt, J. D., Gallinghouse, G. J., Zagrodzky, J. D., Kozeluhova, M., and Natale, A. (2010). Omega-3 polyunsaturated fatty acid supplementation reduced atrial fibrillation recurrence after pulmonary vein antrum isolation.
Indian Pacing Electrophysiol. J. 9, 292-298.

Peltier, S., Louchami, K., Zhang, Y., Portois, L., Hacquebard, M., Malaisse, W. J., and Carpentier, Y. A. (2009) Alteration of lipid fatty acid profile and cationic fluxes in ventricular cardiomyocytes from omega3depleted rats. Int. J. Mol. Med. 24, 343-352.

Pottala, J. V., Garg, S., Cohen, B. E. Whooley, M. A., and Harris, W. S. (2010). Blood Eicosapentaenoic and docosahexaenoic acids predict allcause mortality in patients with stable coronary heart disease: the heart and soul study. Circ. Cardiovasc. Qual. Outcomes 3, 406-412.

Pratt, C. M., Reiffel, J. A., Ellenbogen, K. A., Naccarelli, G. V., and Kowey, P. R. (2009). Efficacy and safety of prescription omega-3-acid ethyl esters for the prevention of recurrent symptomatic atrial fibrillation: a prospective study. Am. Heart J. 158, 163-169.

Raitt, M. H. (2009). Are n-3 polyunsaturated fatty acids antiarrhythmic in the absence of ischemia? Editorial to: "the role of n-3 PUFAs in preventing the arrhythmic risk in patients with idiopathic dilated cardiomyopathy" by S. Nodari et al. Cardiovasc. Drugs Ther. 23, 1-3.

Ramadeen, A., Connelly, K. A., LeongPoi, H., Hu, X., Fujii, H., Van Krieken, R., Van Laurent, G., Holub, B. J., Bazinet, R. P., and Dorian, P. (2012). N-3 polyunsaturated fatty acid supplementation does not reduce vulnerability to atrial fibrillation in remodeling atria. Heart Rhythm. PMID: 22342864. [Epub ahead of print].

Ramadeen, A., Laurent, G., dos Santos, C. C., Hu, X., Connelly, K. A., Holub, B. J., Mangat, I., and Dorian, P. (2010). n-3 Polyunsaturated fatty acids alter expression of fibrotic and hypertrophic genes in a dog model of atrial cardiomyopathy. Heart Rhythm 7, 520-528.

Rauch, B., Schiele, R., Schneider, S., Diller, F., Victor, N., Gohlke, H., Gottwik, M., Steinbeck, G., Del Castillo, U., Sack, R., Worth, H., Katus, H., Spitzer, W., Sabin, G., Senges, J., and OMEGA Study Group. (2010). OMEGA, a randomized, placebo-controlled trial to test the effect of highly purified omega3 fatty acids on top of modern guideline-adjusted therapy after myocardial infarction. Circulation 122, 2152-2159.

Rauch, B., Schiele, R., Schneider, S., Gohlke, H., Diller, F., Gottwik, M., Steinbeck, G., Heer, T., Katus, H.,
Zimmer, R., Erdogan, A., Pfafferott, C., Senges, J., and OmegaStudy Group. (2006). Highly purified omega-3 fatty acids for secondary prevention of sudden cardiac death after myocardial infarctionaims and methods of the OMEGAstudy. Cardiovasc. Drugs Ther. 20, 365-375.

Richardson, E. S., Iaizzo, P. A., and Xiao, Y. F. (2011). Electrophysiological mechanisms of the anti-arrhythmic effects of omega-3 fatty acids. J. Cardiovasc. Transl. Res. 4, 42-52.

Sala-Vila, A., Harris, W. S., Cofán, M., Pérez-Heras, A. M., Pintó, X. Lamuela-Raventós, R. M., Covas, M. I., Estruch, R., and Ros, E. (2011). Determinants of the omega- 3 index in a Mediterranean population at increased risk for CHD. Br. J. Nutr. 106, 425-431.

Saravanan, P., Bridgewater, B., West, A. L., O’Neill, S. C., Calder, P. C., and Davidson, N. C. (2010). Omega3 fatty acid supplementation does not reduce risk of atrial fibrillation after coronary artery bypass surgery: a randomized, doubleblind, placebo-controlled clinical trial. Circ. Arrhythm. Electrophysiol. 3, 46-53.

Savelieva, I., Kakouros, N., Kourliouros, A., and Camm, A. J. (2011). Upstream therapies for management of atrial fibrillation: review of clinical evidence and implications for European Society of Cardiology guidelines. Part II: secondary prevention. Europace 13, 610-625.

Schrepf, R., Limmert, T., Weber, P. C., Theisen, K., and Sellmayer, A. (2004). Immediate effects of n-3 fatty acid infusion on the induction of sustained ventricular tachycardia. Lancet 363, 1441-1442.

Schuchardt, J. P., Neubronner, J., Kressel, G., Merkel, M., von Schacky, C., and Hahn, A. (2011). Moderate doses of EPA and DHA from re-esterified triacylglycerols but not from ethyl-esters lower fasting serum triacylglycerols in statin-treated dyslipidemic subjects: results from a six month randomized controlled trial. Prostaglandins Leukot. Essent. Fatty Acids 85, 381-386.

Shearer, G. C., Pottala, J. V., Spertus, J. A., and Harris, W. S. (2009). Red blood cell fatty acid patterns and acute coronary syndrome. PLOS ONE 4, e5444. doi:10.1371/journal.pone.0005444

Shen, J., Johnson, V. M., Sullivan, L. M., Jacques, P. F., Magnani, J. W., Lubitz, S. A., Pandey, S., Levy, D., Vasan, R. S., Quatromoni, P. A., Junyent, M., 
Ordovas, J. M., and Benjamin, E. J. (2011). Dietary factors and incident atrial fibrillation: the Framingham Heart Study. Am. J. Clin. Nutr. 93, 261-236.

Skuladottir, G. V., Heidarsdottir, R., Arnar, D. O., Torfason, B., Edvardsson, V., Gottskalksson, G., Palsson, R., and Indridason, O. S. (2011). Plasma n-3 and n-6 fatty acids and the incidence of atrial fibrillation following coronary artery bypass graft surgery. Eur. J. Clin. Invest. 41, 995-1003.

Smith, P. J., Blumenthal, J. A., Babyak, M. A., Georgiades, A., Sherwood, A., Sketch, M. H. Jr., and Watkins, L. L. (2009). Association between n-3 fatty acid consumption and ventricular ectopy after myocardial infarction. Am. J. Clin. Nutr. 89, 1315-1320.

Streppel, M. T., Ocké, M. C., Boshuizen, H. C., Kok, F. J., and Kromhout, D. (2008). Longterm fish consumption and n-3 fatty acid intake in relation to (sudden) coronary heart disease death: the Zutphen study. Eur. Heart J. 29, 2024-2030.

Tsuburaya, R., Yasuda, S., Ito, Y., Shiroto, T., Gao, J. Y., Ito, K., and Shimokawa, H. (2011). Eicosapentaenoic acid reduces ischemic ventricular fibrillation via altering monophasic action potential in pigs. J. Mol. Cell. Cardiol. 51, 329-336.
Virtanen, J. K., Mursu, J., Voutilainen, S., and Tuomainen, T. P. (2009). Serum long-chain n-3 polyunsaturated fatty acids and risk of hospital diagnosis of atrial fibrillation in men. Circulation 120, 2315-2323.

Viviani Anselmi, C., Ferreri, C., Novelli, V., Roncarati, R., Bronzini, R., Marchese, G., Somalvico, F., Condorelli, G., Montenero, A. S., and Puca, A. A. (2010). Fatty acid percentage in erythrocyte membranes of atrial flutter/fibrillation patients and controls. J. Interv. Card. Electrophysiol. 27, 95-99.

von Schacky, C. (2008). Omega-3 fatty acids pro-arrhythmic, antiarrhythmic or both ? Curr. Opin. Clin. Nutr. Metab. Care 11, 94-99.

von Schacky, C. (2010). Omega-3 fatty acids vs. cardiac disease - the contribution of the omega-3 index. Cell. Mol. Biol. (Noisy-le-grand) 56, 93-101.

von Schacky, C. (2011). The omega-3 index as a risk factor for cardiovascular diseases. Prostaglandins Other Lipid Mediat. 96, 94-98.

Watanabe, E., Sobue, Y., Sano, K., Okuda, K., Yamamoto, M., and Ozaki, Y. (2011). Eicosapentaenoic acid for the prevention of recurrent atrial fibrillation. Ann. Noninvasive Electrocardiol. 16, 373-378.

Wilhelm, M., Tobias, R., Asskali, F., Kraehner, R., Kuly, S., Klinghammer, L., Boehles, H., and Daniel, W.
G. (2008). Red blood cell omega3 fatty acids and the risk of ventricular arrhythmias in patients with heart failure. Am. Heart J. 155, 971-977.

Wu, J. H., Lemaitre, R. N., King, I. B., Song, X., Sacks, F. M., Rimm, E. B., Heckbert, S. R., Siscovick, D. S., and Mozaffarian, D. (2012). Association of plasma phospholipid long-chain omega-3 fatty acids with incident atrial fibrillation in older adults: the cardiovascular health study. Circulation 125 , 1084-1093.

Xiao, Y. F., Sigg, D. C., Ujhelyi, M. R., Wilhelm, J. J., Richardson, E. S. and Iaizzo, P. A. (2008). Pericardial delivery of omega-3 fatty acid: a novel approach to reducing myocardial infarct sizes and arrhythmias. Am. J. Physiol. Heart Circ. Physiol. 294, H2212-H2218.

Yokoyama, M., Origasa, H., Matsuzaki, M., Matsuzawa, Y., Saito, Y., Ishikawa, Y., Oikawa, S., Sasaki, J., Hishida, H., Itakura, H., Kita, T., Kitabatake, A., Nakaya, N., Sakata, T., Shimada, K., Shirato, K., and Japan EPA lipid intervention study (JELIS) Investigators. (2007). Effects of eicosapentaenoic acid on major coronary events in hypercholesterolaemic patients (JELIS): a randomised open-label, blinded endpoint analysis. Lancet 369, 1090-1098.
Zeghichi-Hamri, S., de Lorgeril, M., Salen, P., Chibane, M., de Leiris, J., Boucher, F., and Laporte, F. (2010). Protective effect of dietary $\mathrm{n}-3$ polyunsaturated fatty acids on myocardial resistance to ischemiareperfusion injury in rats. Nutr. Res. 30, 849-857.

Conflict of Interest Statement: In the last 3 years, the author has received speaker's honoraria from Solvay/Abbott, Pronova, and DSM. Through the University of Munich, research was funded by Smartfish and Sanofi-Aventis. The author has founded Omegametrix, a company offering fatty acid analyses.

Received: 19 December 2011; accepted: 23 March 2012; published online: 17 April 2012.

Citation: von Schacky C (2012) Omega3 fatty acids: anti-arrhythmic, proarrhythmic, or both? Front. Physio. 3:88. doi: 10.3389/fphys.2012.00088

This article was submitted to Frontiers in Cardiac Electrophysiology, a specialty of Frontiers in Physiology.

Copyright (C) 2012 von Schacky. This is an open-access article distributed under the terms of the Creative Commons Attribution Non Commercial License, which permits non-commercial use, distribution, and reproduction in other forums, provided the original authors and source are credited. 